\title{
Study on the Influence of Population Aging on China's Economic Development Based on Individual Fixed Effect Model
}

\author{
Xinying Liu" ${ }^{* 1, \mathrm{a}}$,Yuqi Chen ${ }^{1, \mathrm{~b}}$,Qishan $\mathrm{Mu}^{1, \mathrm{c}}$ \\ ${ }^{1}$ Shandong University of Finance and Economic Faculty of International Economics and Trade Jinan, China
}

\begin{abstract}
In recent years, the aging process of China's population has been accelerating, which has a series of impacts on China's economic development. This paper first analyzes the positive and negative effects of population aging on China from the perspective of theory. Then based on the panel data of 31 provinces in China from 1998 to 2017, this paper establishes individual fixed effect model through unit root test, cointegration test, F-test and Hausman test. The result of the model estimation is that the aging of population can promote the economic development of China and the elasticity of GDP per capita to the ratio of the elderly population is 0.05 . According to this analysis, this paper provides some policy suggestions for China's future economic development.
\end{abstract}

\section{Introduction}

Since 1990s, China's aging process is accelerating. As the country with the largest population in the world, the aging of population affects China's economic development to a certain extent. Based on this, this paper studies from the following three aspects:

- Explore the influence mechanism of population aging on economic development. On the basis of economic theory, this paper discusses the positive and negative effects of aging on the level of economic development.

- Make an empirical analysis of the impact of population aging on China's economic development. Based on the panel data of 31 provinces in China from 1998 to 2017, an individual fixed effect model is established to explore the impact of population aging on China's economy.

- Draw relevant conclusions from the estimated results of the model and put forward effective policy suggestions.

The research in this paper can help us better understand the impact of population aging on China's economy, improve and develop the theory of population aging, and formulate relevant policies for the country.

\section{The Influence Mechanism of Population Aging on Economic Development}

\subsection{Positive Effects of Population Aging on Economic Development}

First, the increase in the elderly population increases the marginal consumption tendency and stimulates consumption. The elderly belong to the "consumer" population in the economy. The increase of the elderly population leads to the increase of the proportion of income used by residents for consumption, and the role of consumption in promoting the economy will be more prominent.

Second, population aging promotes investment in human capital and promotes independent innovation. Because of the increase of life expectancy and the increase of return on investment of human capital, the aging of population may lead to the increase of investment of human capital, which will lead to the improvement of labor education level. Scientific and technological innovation ability is improved and $\mathrm{R} \& \mathrm{D}$ innovation investment increased, which promote the independent innovation development of China's economy.

Third, the aging of the population has led to the development of the pension industry. With the improvement of people's living standard, the elderly have gradually improved their requirements for the quality of life. They pursue more spiritual satisfaction, which in a sense promotes the development of the pension industry. Fourth, to some extent, the deepening of population aging will urge the government to increase investment in infrastructure such as public pension institutions and government medical and health expenditure. As a result, the accelerated process of population aging will increase the purchase expenditure of the authorities.

Fourth, to some extent, the deepening of population aging will encourage the government to increase investment in infrastructure such as public pension institutions and government health expenditure. As a result, the accelerated process of population aging will increase the purchase expenditure of the authorities.

\footnotetext{
a*sheila_guo1988@hotmail.com

b845905475@qq.com c1693352612@qq.com
} 


\subsection{Negative Effects of Population Aging on Economic Development}

First, the increase of the elderly population leads to the decrease of residents' disposable income and the suppression of residents' consumption. Some scholars have established econometric models for analysis, and concluded that population aging will inhibit the improvement of residents' consumption level.

Second, aging reduces material capital investment. According to the basic equation of the Solow model, the increase of the proportion of the elderly population makes the overall savings rate of the society decline and leads to a decrease in the increment of capital per capita, which means that the investment in material capital is reduced, thus inhibiting the economic development.

Third, the aging population will reduce our trade surplus. With the aggravation of population aging and the increase of labor cost, the demographic dividend of China gradually disappears, and the cheap labor force no longer prevails. The competitive advantage of China's manufacturing goods in the international market is gradually weakened, leading to the reduction of China's exports of goods and services and the reduction of trade surplus.

Fourth, population aging reduces output growth. According to the mathematical derivation of CobbDouglas production function, the sources of economic growth are labor, capital, technological progress and institutional innovation. Based on this theory, the following analysis can be drawn: Firstly, the aggravation of aging directly reduces the supply of labor force and leads to slow output growth; secondly, population aging means that the proportion of young people is declining, so that it may not be conducive to technological innovation and technological progress, leading to a decline in total factor productivity and economic growth.

\section{An Empirical Analysis of the Impact of China's Population Aging on Economic Development}

\subsection{Selection of Indicators and Data}

In order to investigate the influence direction of population aging on the level of economic development, this paper intends to use the panel data of 31 provinces, cities and autonomous regions in China from 1998 to 2017 for empirical analysis. The indicators selected for the model are as follows: the level of economic development is measured by per capita regional gross domestic product $p g d p$ (yuan); the level of aging is measured by the proportion of older persons over 65 years of age of the total population $\operatorname{opp}$ (percentage); material capital is measured by the investment in fixed assets of the whole

\footnotetext{
1 The calculation method of per capita education years could be shown as $e d u c=\frac{\sum_{i=1}^{5}\left(e d u c_{i} \times P_{i}\right)}{P}$.

society fai(billion yuan); human capital is measured by years of education per capita $e d u c(\text { year })^{1}$; and foreign openness is measured by the import and export volume of foreign-invested enterprises $\operatorname{tm} x(\$ 10,000)$.

A regression analysis of panel data is performed using Eviews6.0 software. Because the above variable data are absolute, in order to eliminate the heteroscedasticity caused by different units of data measurement, the logarithmic processing of these data is carried out to reduce the fluctuation range. Descriptive statistical analysis of indicators is shown in table I .

TableI. Descriptive statistics of key indicators

\begin{tabular}{|c|c|c|c|c|c|}
\hline Statistics & $\ln (p g d p)$ & $\ln ($ opp $)$ & $\ln (f a i)$ & $\ln (e d u c)$ & $\ln (\operatorname{tm} x)$ \\
\hline Mean & 9.8866 & 2.1563 & 8.1474 & 2.0945 & 13.500 \\
\hline Median & 9.9602 & 2.1610 & 8.1693 & 2.1119 & 13.487 \\
\hline Maximum & 11.768 & 2.8992 & 10.919 & 2.5388 & 20.194 \\
\hline Minimum & 7.7681 & 1.3987 & 3.7199 & 1.0811 & 4.4998 \\
\hline \begin{tabular}{|l|} 
Standard \\
deviation
\end{tabular} & 0.8888 & 0.2517 & 1.4233 & 0.1772 & 3.2586 \\
\hline Skewness & -0.1049 & -0.176 & -0.3117 & -1.7662 & -0.2029 \\
\hline Kurtosis & 2.0391 & 2.8445 & 2.4935 & 9.7577 & 2.5307 \\
\hline Obs & 620 & 620 & 620 & 620 & 620 \\
\hline
\end{tabular}

\subsection{Stability Test}

Because the time series is not necessarily stable, in order to avoid pseudo regression and ensure the validity of parameter estimation, we first test the stability of the sequence. The unit root test of all variables shows that the studied sequence is a first order single integer sequence, and the test results are shown in Table II.

TableII. The Results of Unit Root Test

\begin{tabular}{|l|l|l|l|l|l|}
\hline \multicolumn{1}{|c|}{ Series } & \multicolumn{1}{c}{ (lnpgdp) } & $\boldsymbol{d}($ (nopp) & $\boldsymbol{d}($ (nfai) & $\boldsymbol{d}($ (neduc) & $\boldsymbol{d}(\mathbf{I n t m} \boldsymbol{x})$ \\
\hline Statistics & 119.70 & 315.32 & 108.50 & 383.82 & 277.43 \\
\hline Prob. & 0.0000 & 0.0000 & 0.0002 & 0.0000 & 0.0000 \\
\hline
\end{tabular}

\subsection{Johansen Cointegration Test}

The original sequence is a first order monolithic sequence, so we can choose to do the first order difference processing on the original sequence first, and then regression. But this may cause the economic meaning of the parameters in the model to change. If we want to perform regression analysis on the original panel data, we need to cointegration test on the original sequence to determine whether there is a long-term equilibrium relationship between variables. The Johansen cointegration test results are shown in Table III.

education years of various education levels: 16 years per capita education for junior college or above, 12 years per capita education for senior high school (including technical secondary school), 9 years per capita education for junior high school, 6 years per capita education for primary school, and 1 year per capita education for illiterate people (people aged 15 and over who are illiterate or have little literacy). 
TableIII. The Results of Johansen Cointegration test

\begin{tabular}{|c|c|c|}
\hline Original hypothesis & $\begin{array}{c}\text { Fisher Joint } \\
\text { Trace Statistics } \\
\text { (Prob.) }\end{array}$ & $\begin{array}{c}\text { Fisher Joint } \lambda \text { - } \\
\text { max Statistics } \\
\quad(\text { Prob.) }\end{array}$ \\
\hline 0 cointegration vector & $1196(0.0000)$ & $775.5(0.0000)$ \\
\hline $\begin{array}{lll}\text { Up to } 1 & \text { cointegration } \\
\text { vector }\end{array}$ & $654.7(0.0000)$ & $435.4(0.0000)$ \\
\hline $\begin{array}{l}\text { Up to } 2 \text { cointegration } \\
\text { vectors }\end{array}$ & $309.0(0.0000)$ & $197.8(0.0000)$ \\
\hline $\begin{array}{l}\text { Up to } 3 \text { cointegration } \\
\text { vectors }\end{array}$ & $176.2(0.0000)$ & $150.6(0.0000)$ \\
\hline $\begin{array}{l}\text { Up to } 4 \text { cointegration } \\
\text { vectors }\end{array}$ & $118.3(0.0000)$ & $118.3(0.0000)$ \\
\hline
\end{tabular}

Johansen cointegration test results show that there is a cointegration relationship between per capita GDP and panel data of various explanatory variables, so we can establish a regression model of panel data, and then analyze the impact of population aging on the economy.

\subsection{Granger Causality Test}

In order to determine whether there is a causal relationship between population aging and economic development level, Granger causality test is carried out first, and the test results are shown in Table IV:

TableIV. The Results of Granger Causal test

\begin{tabular}{|l|l|c|}
\hline \multicolumn{1}{|c|}{ Original hypothesis } & F-statistics & Prob. \\
\hline lnopp is not the Granger reason of lnpgdp & 7.8866 & 0.0051 \\
\hline lnpgdp is not the Granger reason of lnopp & 5.1558 & 0.0235 \\
\hline
\end{tabular}

It can be seen from the test results in Table IV that when the significant level is $95 \%$, the original hypothesis is rejected. This shows that population aging is the Granger cause of economic development level, and economic development is also the Granger cause of aging. The following model specifically analyzes the impact of population aging on China's economic development level.

\subsection{Model selection and construction}

Panel data regression models usually have three forms to choose from: one is mixed regression model, the other is fixed effect regression model, and the third is random effect regression model. Mixed regression model means that there is no individual effect and time effect between panel data, which can be mixed together to do least square regression directly. Fixed effect model refers to the existence of fixed effect for these panel data due to time and region. Random effect models are generally used for randomly selected samples.

F-test is usually used when choosing whether to use a mixed estimation model or a fixed effect model. Hausman tests are usually used to determine which model to use in random effect models and fixed effect models.

\subsubsection{F-test}

The test assumptions are as follows:

$\mathrm{H}_{0}$ : Use Mixed Regression Model

$\mathrm{H}_{1}$ : Use Fixed Effect Regression Model
A F-test of the model was conducted as follows:

$$
\begin{aligned}
\mathrm{F} & =\frac{(R R S S-U R S S) /(N-1)}{U R S S /(N T-N-K+1)}=\frac{(103.7089-5.078550) /(31-1)}{5.078550 /(620-31-4+1)} \\
& =379.3562>F_{0.05}(30,586)=1.32
\end{aligned}
$$

where the RRSS and URSS are the sum of the residual squares of the mixed regression model and the fixed effect regression model. $\mathrm{N}$ is the number of sections, $\mathrm{T}$ is the number of time series, and $\mathrm{K}$ is the number of explanatory variables. The result obtained by F-test is to reject the original hypothesis at $95 \%$ confidence level, so the fixed effect model is chosen in the mixed estimation model and the fixed effect model.

\subsubsection{Hausman Test}

The test assumptions are as follows:

$\mathrm{H}_{0}$ : Use Random Effect Regression Model

$\mathrm{H}_{1}$ : Use Fixed Effect Regression Model

The random effect model is first established with panel data and then Hausman tested. The Prob obtained is 0 and the original assumption is rejected at $95 \%$ confidence level. So we should choose the fixed effect model in the random effect model and the fixed effect model.

\subsubsection{Construction of the Model}

From the above F-test and the Hausman test, we determined that a fixed effect model should be established. The fixed effect model includes three types: individual fixed effect model, time fixed effect model and time and individual fixed effect model. Below we construct the individual fixed effect model to carry on the analysis.

As the effect of population aging on economic growth can be described by Cobb-Douglas production function , the basic are as follows:

$$
\begin{aligned}
\operatorname{pgdp}_{i t} & =f(\text { opp }, \text { fai }, \text { educ }, t m x) \\
& =A_{i t} \bullet \text { opp }{ }_{i t}^{\beta_{1}} \bullet \mathrm{fai}_{i t}^{\beta_{2}} \bullet \text { educ }{ }_{i t}^{\beta_{3}} \bullet \operatorname{tmx}{ }_{i t}^{\beta_{4}} \bullet e^{\varepsilon_{i t}}
\end{aligned}
$$

The results can be obtained by taking the logarithm on both sides of the (1):

$$
\begin{aligned}
& \ln \left(p g d p_{i t}\right)=\ln \left(A_{i t}\right)+\beta_{1} \ln \left(o p p_{i t}\right)+\beta_{2} \ln \left(f a i_{i t}\right) \\
& +\beta_{3} \ln \left(e d u c_{i t}\right)+\beta_{4} \ln \left(t m x_{i t}\right)+\varepsilon_{i t}
\end{aligned}
$$

Individual fixed effect model is a model with different intercept terms for different individuals without time influence. Its formula is as follows:

$$
y_{i t}=\delta+\lambda_{i}+\sum_{k=1}^{K} \beta_{k} x_{k i t}+u_{i t}
$$

By substituting the corresponding variables in (2) into (3), we can conclude that:

$$
\begin{aligned}
\ln \left(\operatorname{pgdp_{it}}\right) & =\beta_{1} \ln \left(\text { opp }_{i t}\right)+\beta_{2} \ln \left(f a i_{i t}\right)+\beta_{3} \ln \left(e d u c_{i t}\right) \\
& +\beta_{4} \ln \left(t m x_{i t}\right)+\varepsilon_{i t}+\sum_{j=1}^{31} u_{j} D_{j}
\end{aligned}
$$

The $\beta_{1}, \beta_{2}, \beta_{3}, \beta_{4}$ represents the influence coefficient of explanatory variable $\ln (o p p), \ln (f a i), \ln (e d u c), \ln (t m x)$ on the explained variable $\ln (p g d p)$, that is, the elasticity coefficient of per capita GDP on aging degree, material capital investment, human capital investment and opening to the outside world. Label $\mathrm{i}$ and $\mathrm{t}$ represent provinces and years respectively, $u_{j}$ represents the value of the intercept term of the $\mathrm{j}$ province, $\varepsilon_{\mathrm{it}}$ is the residual term, the virtual 


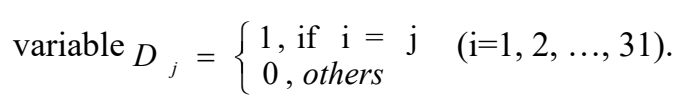

\subsection{Results of Model Estimates}

An individual fixed effect model is established with panel data in Eviews6.0 software. The regression results are shown in Table $\mathrm{V}$ :

TableV. Estimates of Individual Fixed Effect Model

\begin{tabular}{|l|l|l|l|l|l|l|}
\hline Inopp & Infai & Ineduc & Intmx & $\begin{array}{c}\text { F- } \\
\text { statistics }\end{array}$ & $\begin{array}{c}\text { Adjust- } \\
\text { ed } \boldsymbol{R}^{2}\end{array}$ & $\begin{array}{c}\text { Square } \\
\text { sum of } \\
\text { residuals }\end{array}$ \\
\hline $\begin{array}{l}0.0493 \\
*\end{array}$ & $\begin{array}{l}0.5297 \\
* *\end{array}$ & $\begin{array}{l}0.8580 \\
* *\end{array}$ & $\begin{array}{l}0.0422 \\
* *\end{array}$ & 2545.8 & 0.9929 & 5.0786 \\
\hline $\begin{array}{l}(1.6819) \\
(60.960)\end{array}$ & $\begin{array}{l}(10.997) \\
(12.287)\end{array}$ & & & \\
\hline
\end{tabular}
Notes: a. *** indicates significant at 10\% and 5\% levels respectively.
b. Figures in parentheses represent t-statistics.

According to Table V, at $90 \%$ confidence level, the panel model of individual fixed effect is established, while the adjusted $\mathrm{R}^{2}$ is 0.9929 and the fitting effect is better. By substituting the corresponding data in the above table into the (4), the economic growth equation of the i province can be obtained:

$$
\begin{aligned}
\ln \left(\operatorname{pgdp}_{i t}\right)= & 0.0493 * \ln \left(\text { opp }_{i t}\right)+0.5297 * \ln \left(\text { fai }_{i t}\right) \\
& (1.6819) \quad(60.960) \\
+ & 0.8580 * \ln \left(\mathrm{educ}_{\mathrm{it}}\right)+0.0422 * \ln \left(\mathrm{tmx}_{\mathrm{it}}\right) \\
& (10.997) \quad(12.287) \\
+ & 3.7276 D_{1}+3.7835 D_{2}+3.5838 D_{3} \\
+ & \cdots+3.2674 D_{31}+\varepsilon_{\mathrm{it}} \\
\overline{\mathrm{R}}^{2}= & 0.992897 \quad, \quad \mathrm{~F}=2545.864
\end{aligned}
$$

\subsection{Interpretation of the Model}

According to the estimated results of the above model, all the estimated parameters are positive, indicating that when other factors remain unchanged, when the aging of the population deepens, the stock of material and human capital increases, and the degree of external development deepens, per capita output increases, that is, these explanatory variables play a role in promoting economic development.

Specifically, the elasticity of GDP per capita to the ratio of the elderly population is 0.05 , the elasticity to the fixed assets investment of the whole society is 0.53 , the elasticity to the education level per capita is 0.86 , and the elasticity to the import and export volume of foreign investment is 0.04 . Comparing the estimated results of each parameter, we can see that at present, among these factors, human capital has made the greatest contribution to the economic development of China, followed by material capital. And the degree of aging and the degree of opening to the outside world to economic development is not very big.

Adjusted $\mathrm{R}^{2}=0.992897$ indicates that the goodness of fit of the model is good. $\mathrm{F}=2545.864>\mathrm{F}_{0.05}(30,586)=$ 1.32 shows that the equation is significant as a whole. $t$ $=1.682>\mathrm{t}_{0.1}(615)=1.65$ at a given $\alpha=0.1$ means rejecting the original hypothesis. That is, population aging has a significant impact on per capita output.

\section{Conclusions and Suggestions}

Based on the panel data of 31 provinces and autonomous regions from 1998 to 2017 , this paper finally establishes the individual fixed effect model of population aging on China's economic development level after a series of tests. In order to ensure the robustness of the estimated results of the model, three control variables are introduced into the regression model: the investment of fixed assets in the whole society, the years of education per capita, and the import and export of enterprises with foreign investment. According to the regression results, the influence coefficient of population aging on per capital GDP is positive, which indicates that population aging plays a role in promoting economic development.

Based on the above conclusions, we put forward the following suggestions : Firstly, we could stimulate consumption among the elderly. Secondly, we should vigorously develop the pension industry and promote the optimization and upgrading of the industrial structure. Thirdly, we should appropriate delays in retirement and full use of human capital for older persons. In short, in the face of aging population, we must actively and bravely deal with, to firmly grasp this development opportunity.

Population aging brings many social problems, but also creates opportunities for economic development, especially the development of tertiary industry. Therefore, in the face of population aging, an inevitable outcome of economic development to a certain extent, we do not have to panic, but we should also attach great importance to it, face it with a positive attitude, seize the opportunities brought by population aging, give full play to the positive effects of aging and open up a new path for economic development in the new era.

\section{References}

1. Bloom, David E.,Williamson, Jeffrey G. Demographic Transitions and Economic Miracles in Emerging Asia[J]. The World Bank Economic Review, Vol.12, Issue 3. 1998. pp 419-455.

2. Bloom, Canning. Implications of population aging for economic growth[J]. Oxford Review of Economic Policy, 2010, 26(4).

3. Arrow.K., Sen, A.K., Suzumura,K., Handbook of Social Choice And Welfare, Vol.1, Amsterdam, Netherlands: Elsevier, 2002.

4. Li Lu, Zhao Yufeng, Ji Jingyao. A Study on the Coordinated Development of Aging Cause and Industry under the Background of Population[J]. Macroeconomics, 2020(10): 103-113.

5. Li Jianmin, Wang Jingjing. An International Comparative Study on Economic Growth with Aging Populations[J]. Nankai Journal(Philosophy, Literature and Social Science Edition), 2020(04): 6576. 
6. He Dongmei, Liu Peng. Population Aging, Manufacturing Transformation and Upgrade, and High-quality Economic Development-Based on Mediating Effect Model[J]. Research on Economics and Management, 2020, 41(01): 3-20. 